\title{
Editorial: Advanced Thermoplastic Composites and Manufacturing Processes
}

\author{
Patricia Krawczak ${ }^{1,2 *}$ and Alfonso Maffezzoli ${ }^{3 *}$ \\ ${ }^{1}$ IMT Lille Douai, Institut Mines-Télécom, Polymers and Composites Technology \& Mechanical Engineering (TPCIM) Research \\ Lab, Douai, France, ${ }^{2}$ Université de Lille, Lille, France, ${ }^{3}$ Department of Engineering for Innovation, University of Salento, \\ Lecce, Italy
}

Keywords: thermoplastic composites, composites manufacturing, compression molding, pultrusion, overmolding, welding, solid-state drawing, electrospinning

\section{Editorial on the Research Topic}

\section{Advanced Thermoplastic Composites and Manufacturing Processes}

The growing concerns about the environment and energy have driven the widespread adoption of new lightweight materials such as polymer composites in many industrial sectors, crucial issues being performance, cost efficiency, and multifunctionality (Krawczak, 2019). Among them, thermosetting matrix composites offer not only many advantages such as high specific stiffness and strength and their consolidated use in primary aircraft structures but also technical issues such as long processing times, limited fracture toughness, reduction of mechanical properties in the presence of water and solvents, and difficulty of end-of-life treatment (Krawczak, 2011). A key cultural problem is associated with the need of a chemical reaction during part fabrication performed in mechanical/aerospace/naval industries.

Although the use of thermoplastic matrix composites in aeronautic structures has been proposed since the second half of the 80s (Nguyen and Ishida, 1987; Maffezzoli et al., 1989), their first application was at the beginning of the third millennium with the wing leading edge of Airbus A380 (Offringa, 2005). Their demand is continuously increasing (JEC Observer, 2020) since they offer many advantages such as high toughness, long storage time, easy repairing and recycling, higher performances in hot-wet conditions, and ability to be thermoformed and heat-welded. However, manufacturing issues such as high processing temperature, fiber impregnation, and warpage still need a deeper knowledge (Advani and Hsiao, 2012). Thermoplastic composites can play a key role in the 21 st century industry as new materials are emerging day by day, as manufacturing processes are evolving to meet the severe industrial requirements of performance, production, and multifunctionality (Advani and Hsiao, 2012; Boisse, 2015), and as sophisticated numerical simulation tools are making virtual prototyping and engineering more reliable than ever (Binétruy et al., 2015; Boisse, 2015). In that field, innovation is multifaceted and may come either from the constitutive materials (high-performance engineering thermoplastic matrices, commingled semipreg of fibers/thermoplastics, self-healing, bio-based or biodegradable matrices, natural or thermoplastic fibers, 3D textile reinforcement...) or from the manufacturing processes (automated out-of-autoclave processes, hybridization/coupling of technologies, additive manufacturing, hybrid welding...). Moreover, thermoplastic composites allow for automated, high-speed mass production with reduced need for secondary operations (Mafeld, 2014), creating increased interest in the industry for various applications: aerospace and defense, automotive and rail transportation, construction and building, energy, oil and gas, sporting goods, drones, etc. Also, thermoplastic composites offer an interesting recycling potential using mechanical, thermal, or chemical processes (Oliveux et al., 2015). As thermoplastics, it is quite easy to recycle them by regrinding, compounding/blending, and reprocessing; additionally, they are at the forefront of 
current industrial scale-up attempts of chemical recycling, making it possible to recover not only fibers but also feedstock or original monomers which can eventually be re-polymerized to produce new polymers.

This Research Topic focuses on the latest advances and developments of fiber-reinforced thermoplastics, mainly referring to continuous fiber-reinforced composites and of related processing technologies. A collection of seven articles addresses some challenging issues related to advanced manufacturing processes, such as consolidation by compression molding (Ayadi et al.), injection-overmolding (Akkerman et al.), reactive pultrusion (Zoller et al.), joining by ultrasonic (Villegas) or induction (Scarselli et al.) welding, as well as solid-state drawing (Walker et al.) or electrospinning (Sessini et al.) of fibers. Numerical modeling and simulation, and performance assessment through advanced characterization techniques, correlating microstructure and properties, are also addressed.

\section{REFERENCES}

Advani, S. G., and Hsiao, K. T. (2012). Manufacturing Techniques for Polymer Matrix Composites (PMCs). Oxford; Cambridge; Philadelphia, PA; New Delhi: Woodhead Publishing Ltd.

Binétruy, C., Chinesta F., and Keuning, R. (2015). Flows in Polymers, Reinforced Polymers and Composites. A Multiscale Approach. Heidelberg: Springer.

Boisse, P. (2015). Advances in Composites Manufacturing and Process Design. Cambridge: Woodhead Publishing - Elsevier Ltd. doi: 10.1016/C2014-0-02644-5

JEC Observer (2020). Overview of the Global Composites Market 2019-2024. Paris: JEC Group.

Krawczak, P. (2011). Recycling of thermoset structural composites: Would textile technology bring a high added-value solution? Express Polym. Lett. 5:238. doi: 10.3144/expresspolymlett.2011.82

Krawczak, P. (2019). Polymer composites: evolve towards multifunctionality or perish. Express Polym. Lett. 13:771. doi: 10.3144/expresspolymlett. 2019.65

Mafeld, A. (2014). The Automation of Polymer Composites Manufacturing. Paris: JEC Group.
These papers highlight how thermoplastic matrix composites can be processed, adopting a completely different paradigm in comparison to thermosetting matrix ones, the former not requiring a reaction to set the properties but complex thermal cycles, often performed in a short time span.

The Guest Editorial team is confident that this collection of papers will benefit a large community in research and application of advanced thermoplastic composite materials so as to further advance along the pathway toward sustainability, performance, and competitiveness.

\section{AUTHOR CONTRIBUTIONS}

This Editorial was jointly written by the co-authors $\mathrm{PK}$ and AM who also served as Guest Editors for the Research Topic. All authors contributed to the article and approved the submitted version.

Maffezzoli, A., Kenny J. M., and Nicolais L. (1989). Welding of PEEK/carbon fiber composite laminates. SAMPE J. 25:35.

Nguyen, H. X., and Ishida, H. (1987). Poly(aryl-ether-ether-ketone) and its advanced composites: a review. Polym. Compos. 8:57. doi: 10.1002/pc.7500 80202

Offringa, A. (2005). Thermoplastics in aerospace, new products through innovative technology. SAMPE J. 41, 19-27.

Oliveux, G., Dandy L. O., and Leeke G. A. (2015). Current status of recycling of fibre reinforced polymers: review of technologies, reuse and resulting properties. Prog. Mater. Sci. 72, 61-99. doi: 10.1016/j.pmatsci.2015.01.004

Conflict of Interest: The authors declare that the research was conducted in the absence of any commercial or financial relationships that could be construed as a potential conflict of interest.

Copyright (c) 2020 Krawczak and Maffezzoli. This is an open-access article distributed under the terms of the Creative Commons Attribution License (CC BY). The use, distribution or reproduction in other forums is permitted, provided the original author(s) and the copyright owner(s) are credited and that the original publication in this journal is cited, in accordance with accepted academic practice. No use, distribution or reproduction is permitted which does not comply with these terms. 